\title{
Conditions for Effective Collaboration in SME Networks Based on Graph Model
}

\author{
Dario Antonelli, Giulia Bruno, Teresa Taurino, and Agostino Villa \\ Politecnico di Torino, Dept. Management and Production Engineering, \\ Corso Duca degli Abruzzi, 24, \\ 10129 Torino, Italy \\ \{dario.antonelli,giulia.bruno, \\ teresa.taurino, agostino.villa\} @ polito.it
}

\begin{abstract}
Collaboration represents an increasing tendency among Small and Medium Enterprises (SMEs), since the possibility of being a cooperative partner of a network allows the achievement of development strategies, either to improve production processes or to increase competitiveness. The objective of the paper is to propose and apply a new methodology to model manufacturing SME networks in terms of graph matrices, in order to identify some conditions that can foster an effective collaboration among partners of a SME network. A classification of SME networks in four typologies named "Marshallian Network", "Supply chain network", "Hub and Spoke network" and "Scientific Park" will be introduced. For each typology a graph-based model will be used to find out limits and critical points that can hinder the SME collaboration, or focal points for the interaction reinforcing.
\end{abstract}

Keywords: SME networks, collaboration, graph models.

\section{Introduction}

Collaboration represents an increasing tendency among Small and Medium Enterprises (SMEs). It is considered an effective solution allowing the achievement of development strategies $[1,2,3,4,5]$, either to improve production processes or to increase competitiveness based on innovation and quality $[6,7,8,9,10]$.

SME managers usually show a traditional individualistic attitude [11]. Unfortunately, small businesses often suffer in globalized markets from fierce competition in terms of products, labor and finance. On the contrary, being an independent but cooperative partner of a network could be a real possibility to obtain advantages for the SME. For example, by integrating skills of all the network partners the realization of more complex products it's possible; by cumulating SMEs capabilities, manufacturing volumes can increase; by sharing workers and resources, the effects of fluctuations of market demand can be reduced $[12,13,14,15]$.

In the authors' experience (based on the development of the EU-funded project "Collaborative demand and supply networks - CODESNET [16]), to complete the huge amount of papers and books published on the collaboration among SMEs, a 
simple and easily usable model of SME networks is required. It also represents, for the manager, an instrument for the analysis of convenience of collaborative relations in the SMEs network

This paper aims at developing a model of a SME network in terms of a graphbased scheme. The graph model provides a representation of the structure of connections among SMEs and the basic information that any manager has at disposal. Based on this simple approach, four graphs of different network types will be identified. The introduced classification is able to characterize a very large number of different SME aggregations: from industrial districts, to clusters, to poles of competitiveness, up to scientific parks.

The main goal of this paper is that, by considering the configuration of an industrial network to which a manager of a SME could be interested to participate, he/she can assess whether the network is able to support its own activities and its own business, by assuring further profit.

The paper is organized as follows. Section 2 describes the SME network classifications deriving from the experience gained from the CODESNET project. Section 3 introduces the graph-based SME network models and analyzes the four typologies of SME networks in terms of matrices derived from graphs. Finally, Section 4 draws some concluding remarks.

\section{Classification of Network Types}

The utilization of a graph formulation appears to be an important tool in order to provide a layout of a SME network. It also offers a starting point for modeling and analyzing flows and connections between the companies belonging to the network itself. To obtain a graph representation of a SME network, each enterprise (or a group of enterprises grouped according to appropriate criteria and to the desired level of detail) can be modeled by a node of the graph. The arcs between nodes correspond to possible links connecting SMEs; the connections can be either physical (i.e. exchange of materials, resources) or informative (i.e. exchange of information and know-how, transfer of orders).

The classification of the SME network structures has been obtained by using both the available literature on the topic and the concrete examples derived from the CODESNET database. For the derivation of the model, data of 160 industrial networks from 11 different European countries have been used. The classification consists of four graph-based configurations, illustrated in the following figures. In each figure, the network boundaries are represented by a rectangle, the small and medium enterprises belonging to the network, by the numbered circles and connections between SMEs by arcs. For formal issues without a loss of generality, a source node (named S) and a destination node (named D), if not belonging to the network, are introduced as external nodes.

The most common configuration is denoted as Marshallian-Italianate network [17]. A simple topological representation is given in Fig.1. This network is characterized by a set of SMEs, each of them can both provide and receive products / services / information from the others; this can be easily seen by the high number of arcs connecting the nodes. The node $\mathrm{n} .1$ can be considered as a source node belonging to 
the network. Thus, the main characteristic of this topology is that it allows the presence of cycles.

Two examples of networks with this topological structure can be found in Europe. The first example is the Gold District of Valenza ("Distretto Orafo di Valenza"), an industrial district of the North-West Italy specialized in the jewelry production with an important role in the international market. The second district is the ShannonSoft, a network of Software activity in the Shannon Region in Ireland. In both these examples and in all the networks of the first type of configuration, the geographical proximity and the similarity in producing play an important role for the growth of the network.

A second type of SME aggregation has been identified as "supply chain" or, more generally, "multi-stage supply chain" [8]. At the right, in the previous Fig.1, a structure of a Multi-stage supply chain is represented: arrows represent links typically with an exchange of material or components. In the figure, the node n.8 can be considered as a destination node belonging to the network. An example of this organization is the Footwear District ("Distretto delle Calzature di Fermo"), located in the Center of Italy, specialized in the production of shoes.
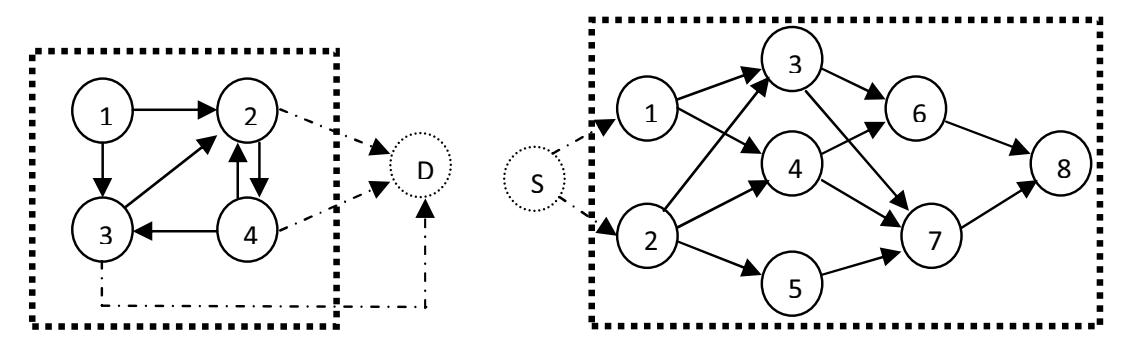

Fig. 1. Graphs of a Marshallian-Italianate network on the left and Multi-stage Supply chain network on the right, where $\mathrm{S}$ is the source node and $\mathrm{D}$ is the Destination node

Products are differentiated in order to cover different market stratification (shoes for man, women and child): to this aim, the chain is composed by stages with a number of parallel SMEs. Unlike the previous configuration, in this network cycles are not allowed.

Some SME aggregations can be described in terms of Hub-and-spoke configuration [17], owing to the presence of a leader in the network that will affect the decisions of all other partners. A simplified graph representation of the hub and spoke type with one leader and five SMEs is given in the next Fig.2. This configuration does not allow cycles and the lead node has a number of entering edges very higher that the other nodes, so it can be considered as a destination node belonging to the network.

The Eyewear District ("Distretto dell'Occhiale di Belluno") in North Italy has a similar configuration: there are 5 leading firms corresponding to important brands of international fame, and around them a network of 1.500 small and medium enterprises specialized in the production of components or in particular production processes. In addition to these three models that represent very fixed and ruled interactions among 
SMEs, there is another kind of aggregation, mainly exploited by high-tech production and/or service supply. Since the nature of such aggregation is mainly oriented to R\&D, this configuration is named Scientific Park (or "pole of competitiveness" in France) [11].

In terms of graph representation (Fig. 2 on the right), the nodes can be considered as inserted in a pre-existing network (light gray in the picture) of services and experience that can create contacts between enterprises that join the Scientific Park. In this configuration, connections are very flexible and more informal than in the other configurations. The typical feature of a Scientific Park is that each node is connected directly with the source and the destination nodes (due to the pre-existing network) and all the possible edges between nodes can be activated or interrupted at any time.
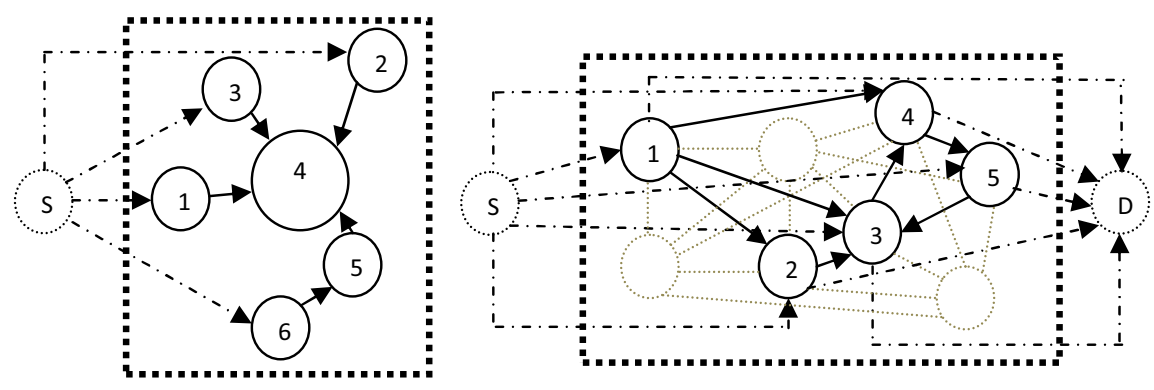

Fig. 2. Graphs of a Hub and Spoke network on the left and of a Scientific Park on the right

The exchanges between such companies does not concern materials or components but is an exchange of information (knowledge, data, models, ideas) and services, thanks to the underlying network of partners specialized in ICT and support to the innovative activities. The pole EMC2 in the "Pays de la Loire" in France, is an example of Scientific Park specialized in the sector of naval construction, aeronautics, yachting and the automotive industry. Another example is the Patras Science Park in Greece which strategic objective is to establish an Innovative Business Area in the Region of West Greece.

\section{Recognizing Conditions for Effective Collaboration from Graph-Based Network Model}

The modeling of a SME network requires to take into account two main aspects:

- the type of connecting structure, that means the organization of links among SMEs and the definition of types of flows on those links; the model of the connection structure is called "structural model" of the network;

- main functionalities to be performed in order to assure an efficient, effective and convenient management of operations of all SMEs in the network: that can be done through a "functional scheme". 


\subsection{Functional Scheme}

The main functionalities that characterizes the SME network management organization can be modeled with a "functional scheme" [5]. The model is useful to give a visual representation of activities such as contribution of partners to the network management committee (if it exists); generation of production and financial strategies by the network committee; translation of strategies into activity plans to satisfy customers orders.

For the evaluation of the network performance, the basic element that should be recognized through the "functional scheme" is the network management committee in terms of its composition and its management tasks. The presence of a committee in a SME aggregation assures a coordination potential; its lack requires existence of a reciprocal trust among SME managers and, possibly, a coordination agreement.

\subsection{Structural Scheme}

From the structural point of view, a SME network can be represented in terms of a graph $G=(V, E)$, where $V$ is the set of vertices and $E$ is the set of edges or arcs. Typically, a vertex can be referred to a component SME, while an edge can represent a SME-to-SME connection.

For the scope of the present analysis concerning network of manufacturing SMEs, the graph under consideration is referred to the physical part flows (i.e., the logistic connections among SMEs).

The following different types of matrix representations could be identified for a graph $G[19,20]$ modeling of a considered real SME network,

- the incidence matrix $M$ [nodes vs edges] that identifies the links outgoing from each node, i.e. the existence of output flows from a given SME;

- the adjacency matrix $R$ [nodes vs nodes] that specifies the existence of all the connections among the nodes, i.e. the existence of flows from a SMEs towards another SME;

- the path matrix $P$ [paths vs edges], that specifies the flows of products between two SMEs operating as suppliers and customers for the production of a specific product; the matrix $\mathrm{P}$, for a particular product, is obtained by placing, for each path, a mark in correspondence with the edges (i.e., column) that belong to the working sequence of the product itself;;

- the distance matrix $L$ [nodes vs nodes], where each element is a certain "magnitude" associated to each edge. The value associated to the edge can be, for example, the geographic distance between the two connected SMEs, the economic cost or the time associated to the transfer of products between the two enterprises. The modified distance matrix $L^{\wedge}$ [paths vs nodes is obtained by placing, for each path associated to a particular product, the average production flow in correspondence with the SMEs (i.e. column) involved in the production.

This set of matrices can support the analysis of any type of SME networks and allows to recognize some conditions of either strong or weak collaboration among SMEs. 
A sufficient analysis of a real SME network, based on above matrices, can be done by knowing the following "basic data":

a) for each product type manufactured by the network,

o the average flows to be produced per unit time (i.e., production volumes);

O the working sequence (i.e., the sequence of SMEs involved to apply the required manufacturing activities);

b) for each component SME, the actual production capacity value, expressed in terms of the global volume of products per unit time that can be processed by the SME, in the average.

The analysis steps to be applied to a given SME network can be illustrated as follows:

$1^{\text {st }}$ step: Compile the following matrices $\mathrm{M}, \mathrm{R}, \mathrm{P}$, and $\mathrm{L}^{\wedge}$;

$2^{\text {nd }}$ step: Compute the production capacity of each SME, by summing all production flows reported in the same column of the modified distance matrix $\mathrm{L}^{\wedge}$, associated with the considered SME.

$3^{\text {rd }}$ step: Apply a cutset recognition procedure to the path matrix $\mathrm{P}$ in order to identify any group of paths (i.e., groups of products that can belong to a same "product family") and the related set of SMEs (that could belong to a same "supply chain").

$4^{\text {th }}$ step: Compute the following indicators:

- network connectivity index (NCO), i.e. the number of non-null elements in matrix R, corresponding to the number of connections among SMEs;

- network utilization balance (NUB), in terms of the percentage number of SMEs for which the difference between the computed production capacity (at step 2) and the actual capacity value (type b data) is greater than a given "sufficient utilization" lower bound;

- network separation into chains (NSC), i.e. percentage number of recognized independent supply chains, if any, referred to the number of component SMEs;

- network chains independence $(\mathrm{NCH})$, in terms of the percentage number of links (i.e., cutsets dimensions) connecting the recognized supply chains, if any;

- number of network bottlenecks.

1-3-D

1-3-2-D

1-2-4-D

1-3-2-4-D

1-2-4-2-D

1-2-4-3-D

1-2-4-3-2-D

\begin{tabular}{|c|c|c|c|c|c|c|c|c|}
\hline $1-2$ & $1-3$ & $2-4$ & $3-2$ & 4-2 & 4-3 & $2-\mathrm{D}$ & $3-D$ & 4-D \\
\hline 1 & & & & & & 1 & & \\
\hline & 1 & & & & & & 1 & \\
\hline & 1 & & 1 & & & 1 & & \\
\hline 1 & & 1 & & & & & & 1 \\
\hline & 1 & 1 & 1 & & & & & 1 \\
\hline 1 & & 1 & & 1 & & 1 & & \\
\hline 1 & & 1 & & & 1 & & 1 & \\
\hline 1 & & 1 & 1 & & 1 & 1 & & \\
\hline
\end{tabular}

Fig. 3. Paths Matrix of a Marshallian-Italianate network 
Referring to the Marshallian-Italianate network type, an evident measure of potential strong collaboration among SMEs is the high number of connections, then high value of NCO. A significant number of non-null element in the path matrix $\mathrm{P}$ in Fig. 3 makes evidence of several loops, then another indication of good collaboration.

In a Multi-Stage network (see Fig. 1), each stage is a set of "parallel" SMEs, and each SME in a same stage could implement different work phases. Then, different parallel supply chains could exist, thus corresponding to low value of the $\mathrm{NCH}$ indicator and high value of the NSC one.

In any type of SME network, existence of independent supply chains can be a cause of a network subdivision into potentially competing and conflicting parts, mainly if the separations between any two supply chains is strong (low NCI).

A different situation occurs in case of a Hub-and-Spoke network, where partial chains could exist, but all converging on a same hub SME. Then, the NSC indicator will be low.

Specific considerations are required by the Scientific-Park type network, where two graphs exist: one composed by the SMEs already operating, and the other defining the set of all links that the park management committee can make at disposal of other new SMEs (i.e. an underlying network whose links can be activated in the future). The former network can have small NCO and almost null NSC. The underlying network, on the contrary, must be characterized by high NCO. Whilst no indicators can be computed for "empty" nodes.

\section{Conclusions}

In this work a bottom-up approach has been used to develop models for SMEs networks analysis. Thanks to the huge experience of analysis gained during the CODESNET project, a classification of different type of SME network has been derived from practices and formally modeled by two models. As shown, the different types of SME networks can be described by a set of matrices (adjacency matrix $R$, incidence matrix $M$, path matrix $P$, distance matrix $L$ and modified distance matrix $L^{\wedge}$ ), in structural terms, and by the functional scheme, in terms of management. A procedure of analysis is also introduced in order to give a guide to conduct the SMEs network analysis and evaluation by the definition of a list of indicators. This represents a significant result of the paper since both the structure and the functionality of a SME network can be associated with few but significant indicators. The two models introduced constitute an important instrument to answer to SME manager requirement: to be able to decide having knowledge of the most critical conditions and information affecting the decision. So, in case a SME manager would like to estimate if its SME could have a profitable return becoming a partner in a network, this approach can give him/her preliminary approximated but significant criteria for taking a decision: whether trying to find an agreement with the network partners or the committee, or not. The type of network and its management, as currently operating, can give him/her the answer. 


\section{References}

1. Antonelli, D., Taurino, T.: Identifying and exploiting the collaboration factors inside SMEs networks. International Journal of Networking and Virtual Organisations 9, 382-402 (2011) ISSN: 1470-9503

2. Villa, A., Taurino, T., Ukovich, W.: Supporting collaboration in European Industrial Districts - The CODESNET approach. Journal of Intelligent Manufacturing, 1-10 (February 25, 2011), doi:10.1007/s10845-011-0516-6

3. Taurino, T., Antonelli, D.: Analysis of Potential Collaborations in SME Networks. In: INCOM 2009 - 13th IFAC Symposium on Information Control Problems in Manufacturing, Moscow, Russia (June 3-5, 2009)

4. Villa, A., Bruno, G.: Promoting SME cooperative aggregations: main criteria and contractual models. International Journal of Production Research (in press)

5. Bruno, G., Villa, A.: An ontology-based model for SME network contracts. In: Herrero, P., Panetto, H., Meersman, R., Dillon, T. (eds.) OTM-WS 2012. LNCS, vol. 7567, pp. 85-92. Springer, Heidelberg (2012)

6. Ravazzi, P., Villa, A.: Economic aspects of industrial automation. In: Handbook of Automation, pp. 93-116. Springer, London (2009)

7. Michaelides, R., Morton, S.C., Michaelides, Z., Lyons, A.C., Liu, W.: Collaboration networks and collaboration tools: a match for SMEs? International Journal of Production Research 51(7), 2034-2048

8. Bogataj, M., Grubbstrom, R.W., Bogataj, L.: Efficient location of industrial activity cells in a global supply chain. International Journal of Production Economics 133(1), 243-250 (2011)

9. Antonelli, D., Caroleo, B., Taurino, T.: Pattern Recognition from Data Collection on Industry Networks. Systems Science 33, 81-90 (2007) ISSN: 0137-1223

10. Taurino, T., Antonelli, D.: An insight into Innovation Patterns of Industrial Districts. In: 6th CIRP International Conference on Intelligent Computation in Manufacturing Innovative and Cognitive Production Technology and Systems, Naples, Italy (July 23-25, 2008)

11. Villa, A. (ed.): Managing Cooperation in Supply Network Structures and Small or Medium-sized Enterprises: Main criteria and tools for managers. Springer, London (2011)

12. Mezgár, I., Kovács, G.L., Paganelli, P.: Co-operative production planning for small- and medium-sized enterprises. International Journal of Production Economics 64, 37-48 (2000)

13. Villa, A., Antonelli, D. (eds.): A Road Map to the Development of European SME Networks - Towards Collaborative Innovation. Springer, London (2009)

14. Bengtsson, M., Kock, S.: "Coopetition" in Business Networks - to Cooperate and Compete Simultaneously. Industrial Marketing Management 29, 411-426 (2000)

15. Camarinha-Matos, L.M., Afsarmanesh, H.: Taxonomy of Collaborative Networks Forms. Final document of the FInES Task Force on Collaborative Networks and SOCOLNET Society of Collaborative Networks

16. CODESNET: Collaborative Demand and Supply Network, European Coordination Action, EU-funded project EU FP7

17. Markusen, A.: Sticky Places in Slippery Space: A Typology of Industrial Districts. Economic Geography 72(3), 293-313 (1996)

18. Molina-Morales, F.X., Martinez-Fernaàndez, T.: The impact of Industrial District Affiliation on Firm Value Creation. European Planning Studies 11(2), 155-170 (2003)

19. Chachra, V., Ghare, P.M., Moore, J.M.: Applications of Graph Theory Algorithms. Elsevier, North Holland (1979)

20. Villa, A.: Hybrid Control Systems in Manufacturing. Gordon \& Breach Science, Amsterdam (1991) 